\title{
Arabic Phonemic Awareness (PA): The Need for an Assessment Tool
}

\author{
Yousef M. Al-Shaboul ${ }^{1}$, Sahail M. Asassfeh ${ }^{1}$, Sabri S. Alshboul ${ }^{2} \&$ Yasser A. Al Tamimi ${ }^{3}$ \\ ${ }^{1}$ Department of Curriculum \& Instruction, College of Education, and English, College of Art, The Hashemite \\ University, Zarqa, Jordan \\ ${ }^{2}$ Department of English, The Hashemite University, Zarqa, Jordan \\ ${ }^{3}$ Alfaisal University, Riyadh, Saudi Arabia \\ Correspondence: Yousef M. Al-Shaboul, Department of Curriculum \& Instruction, College of Education, and \\ English, College of Art, The Hashemite University, Zarqa, Jordan. E-mail: yshbool@hu.edu.jo
}

Received: October 20, 2013 Accepted: November 6, 2013 Online Published: December, 2013

doi:10.5539/ass.v10n1p200 URL: http://dx.doi.org/10.5539/ass.v10n1p200

\begin{abstract}
Phonemic awareness (PA), the consciousness of the sounds of the language, plays an instrumental role in reading development; research confirms that individuals with difficulty in detecting or manipulating sounds in words will struggle with learning to read. In spite of the plethora of instruments assessing PA of other languages, there is a dearth of research addressing PA in Arabic, the mother tongue of no less than 400 million people. Benefitting from previous research in the field, this paper is the first to develop and administer an instrument towards this end. Our proposed instrument, which includes 24 carefully selected words based on the standards of familiarity and feature analysis with a reliability coefficient of 0.93 was administered to 100 participants. The tool categorizes participants into three categories, highlights the role of KG, and reports on words the learners found easy and those difficult to segment. The paper calls for more research to investigate the role of Arabic PA in empowering Arab children's reading ability.
\end{abstract}

Keywords: Arabic, speakers of Arabic, phonemic awareness, phonological awareness, reading

\section{Introduction}

Phonological awareness has gained momentum in the field of literacy during the last few decades with special interest in investigating the contribution of its most sophisticated level, PA to literacy. Phonological awareness, the consciousness of the sounds of the language including syllables, onsets and rimes, and phonemes (Gillet, Temple, \& Crawford, 2004; Layton, Deeny, Upton, \& Tall, 1998; Sensenbaugh, 2000; Stanovich, 1994), encompasses the awareness of, and the ability to manipulate, phonemes including deleting, adding, or substituting (Anthony \& Francis, 2005; Chard \& Dickson, 1999). Recent investigations in language acquisition have addressed the relationship between PA and reading ability (Ehri, 1991; Goswami, 2000; Olofsson \& Niedersoe, 1999) concurring children with reading disabilities could neither segment nor blend the sounds of a spoken word. Without the appropriate assessment tools, these investigations could not have been carried out, such important findings would not have been revealed, and children would have stayed in struggle with reading.

The international literature exhibits a wide variety of tests and tools that measure phonological awareness in general and PA in specific for many languages over the world. The target language of this study, Arabic, is the mother tongue for about 400 million people, the second language for almost a quarter of a billion, the official language of more than twenty Arab countries (Gordon, 2005), and the language of Quran, the holy book for more than one billion Muslims. Nonetheless, to date, there is a clear need for devising a tool that helps L1 educators to assess Arab learners' PA as a requirement for diagnosing the weaknesses to work on and the strengths to enhance towards reading development. Accordingly, this study aimed at both a systematic development of an assessment tool and an assessment for Arabic PA to fill this void in the literature.

\section{Area Description}

PA skills provide children with better chances to become better readers. The National Reading Panel (2000) Report to the U.S. Congress strongly advocates helping children hear sounds in words, know the letters of the alphabets, know letter-to-sound correspondences, and be able to read words (Snow, Burns \& Griffin, 1998). Efficient reading depends heavily on breaking the code of the sound system (Moats, 2000); the secret of reading 
in alphabetical languages lies within the learners' ability to successfully carry out the phoneme-to-grapheme correspondences. In line with this, language teaching starts with establishing, developing, and enhancing the sound system in the learner prior to teaching the letters of the language--an instruction that focuses on PA as both a process and a product. Teachers' main goal at initial stages, accordingly, lies in enabling the learner to consciously manipulate the individual sounds of the language through rhyming, combining, segmenting, adding, and deleting (Chard \& Dickson, 1999).

Since PA is a powerful predictor of reading ability (Hulme, Goetz \& Gooch 2007), success in reading and spelling critically depends on PA that represents the deepest level among phonological awareness components (Anthony \& Lonigan, 2004). Yopp (1992) asserts that phonemically aware children are capable of understanding and manipulating the smallest sounds of language, a predictor for how good as readers they might be later. Stanovich (1994) goes a step further asserting that PA prudently predicts reading achievement even 'better than anything else that we know of, including IQ' (p. 284). Thus, individuals who have difficulty detecting or manipulating sounds in words will struggle with learning to read (Anthony \& Francis 2005; Hatcher, Hulme \& Snowling, 2004; Share, 1995; Snowling, 1998; Vellutino, Fletcher \& Snowling, 2004). Adams (1990) firmly states that if children fail to acquire PA, then they "are severely handicapped in their ability "to master print" (p. 412).

Thus, assessing PA in the right stage is indispensable to uncover any potential obstacles and save children from forthcoming delays or mislabels. All it might take to rescue a child from becoming a poor reader or a late bloomer is to be there at the right time well equipped and ready to offer the help needed. Should this suggest anything, it is the critical need to carry out a rigorous assessment starting from detecting and spotting potential problems, leading to enhancing children's phonological skills and developing their reading abilities. However, to the best of the researchers' knowledge, there is no tool currently available to assess Arabic PA, a graving desire which drives this current endeavor.

\subsection{An Arabic PA Assessment Tool: Theoretical Underpinnings}

Based on a review of the extant literature, several considerations have been taken into account in developing our instrument. To begin with, a child's PA emerges as early as the age of two and extends till the fourth year taking some time to develop, if immersed in literacy rich environment (Troia, 2004). It typically begins during the preschool years when children with normal hearing can attend to ambient sounds by naming, imitating and describing (Olofsson \& Niedersoe, 1999). PA begins with the consciousness of words as units of analysis then proceeds to the awareness that words can share certain ending properties called rhyme; to an awareness that words can be decomposed into syllables, then (possibly though not definitely) more finely into sub-syllabic units called onsets and rimes, and finally (and most importantly for reading) into awareness of individual phonemes, the smallest units of sound analysis (Hempenstall, 2006). One implication is that a successful PA test be carried out on learners just starting their reading process.

Second, Arabic has two forms referred to as diglossia (Ferguson, 1959): the Modern Standard Arabic (MSA) and the spoken Arabic. The former dominates the written and formal contexts while the latter dominates the routine language of the daily life of Arabs. Despite country-specific dialectical differences, all Arab countries share the MSA as the official language. The common practice is that Arab children grow up learning the immediate dialect used in their communities and start learning MSA during their first official literacy encounter. This implies that a PA assessment tool be based on words children encounter in their formal curriculum, rather than in daily-life spoken language.

Third, Arabic has a peculiar nature. Compared to that of other languages, its orthographic system is considered phonologically transparent with a high consistent set of phoneme-grapheme correspondences (Wagner, 1993; Abu Rabia, 1997a, 1999). This transparency, it is presumed, should play a facilitative role in word recognition developed through dependence on phonological processing skills (Abu Rabia, 1997b). Among its 28 letters, the vowel system includes only three long vowels (/i/,/u/, /a/) and three short diacritics (Abu Rabia, 1997a; Wagner, 1993); it utilizes an alphabetic orthography that encodes language at the level of phonemes. Hence, graphemes closely correspond to consonant and vowel phonemes (Fender, 2003). This peculiarity of Arabic makes it logical to expect relatively higher scores in learners' performance on PA tests compared to the scores of learners of less transparent languages.

Fourth, when it comes to phonological awareness development, at one end of the continuum fall the less-complex activities such as initial rhyme and rhyming songs as well as sentence segmentation that demonstrates awareness that speech can be broken down into individual words. At the center are activities related to segmenting words into syllables, blending syllables into words, segmenting words into onsets and 
rimes, and blending onsets and rimes into words. The most sophisticated level of phonological awareness falls at the other end, PA. In terms of the complexity of PA activities, segmenting falls at the center of a continuum, or using Anthony and Francis's (2005) 'developmental sequence', on top of which stands deleting with blending at the bottom. Thus, segmenting is the core of our instrument.

In brief, given the crucial role PA plays in reading, having the right assessment tool makes the task easier to uncover any reading problems children might face during the first years of official schooling. Carrying out the right assessment at the right stage should contribute to preventing probable reading failures as a requisite for providing children with better chances to become better readers. Lacking the appropriate assessment tools is an immense disservice for both Arabic and its speakers.

\subsection{Questions of the Study}

In addition to its main purpose, namely, to design an assessment tool to assess Arabic phonemic awareness, the study targeted the following two questions:

1) To what extent do Jordanian children develop phonemic awareness toward the end of their first grade?

2) Are there any statistically significant differences $(\alpha \leq .05)$ in PA between Jordanian first graders who did and those who did not receive $\mathrm{KG}$ education?

\section{Method}

\subsection{Subjects}

One hundred first graders (49 boys and 51 girls), all Arabic native speakers aged 7 years on average, participated in this study. All children, representing the middle socioeconomic class, came from public elementary schools in the second major city in Jordan. According to their teachers, those learners were beginning readers the majority of whom had already entered kindergarten.

\subsection{Instrumentation}

Although English is described as deep and Arabic as transparent, this study benefitted from the procedures of Yopp-Singer's (1988) Test of English phonemic segmentation which enjoys a reliability of .95, and has been widely used for the purpose of PA assessment. As Rathvon (2004) notes, "The YST has been used in numerous reading investigations to predict reading acquisition and evaluate the effectiveness of early reading intervention programs" (p. 365). The test, administered at individual learners, takes 5-10 minutes with a maximum score of 22 if all words on the test are correctly segmented; one score per word.

The rationale for the relative dependence on this test in the current study is the fact that both languages are alphabetic, a common ground for the two languages to count on when developing comparable tools. It is noteworthy that Yopp-Singer's well-established, quick and easy test comprised 22 words selected based on two criteria: (a) word familiarity and (b) word-feature analysis. Yopp's word familiarity was established based on Thorndike and Lorge's (1963) list of frequently occurring words. Word feature analysis aimed at ensuring that the word list represent all commonly occurring (a) places, (b) types of articulation for consonants, and (c) all heights and locations for vowels. Students' obtained scores, according to Yopp (1995), classify students' PA on a continuum that has three broad categories: (a) developed PA (with correct segmentation of all or nearly all items); (b) emerging (some items correctly segmented); and (c) delayed (only a few or none of the items correctly segmented).

Likewise, the proposed Arabic PA assessment tool adopts the aforementioned guidelines and procedures to measure the child's ability to separately articulate the sounds of spoken words in the correct order. Since speech sounds (consonants and vowels) are classified according to manner and place of articulation for consonants and tongue position for the vowels, the 24 words included in the test represented the most common occurrences of the component sounds. Familiarity in the current study was established on two grounds. The first was content analysis for the vocabulary in Standard Arabic official textbook. This is a common practice in cross-linguistic research when no standardized tests exist (Arab-Moghaddam \& Senechal, 2001; Baluch \& Shahidi, 1991; Bruck, Geneseea \& Caravolas, 1997). Second, Arabic teachers' approval; they acknowledged children being exposed to those words through lessons that include the most-frequently occurring words.

In details, the prepared word list contains different groups of words: (a) monosyllabic words containing diphthongs in closed syllables (e.g. laith, sair, etc); (b) short vowels in closed syllables containing consonant clusters in the coda position (e.g. nahr, nab3, etc); (c) multisyllabic words containing a long vowel in a closed final syllable (e.g. kitaab, dokhool, etc), (d) a long vowel in a closed non-final syllable (e.g. qadam); and (e) words containing short vowels in a closed syllable in different positions: first, second or final (e.g. risalah). 
Whereas Arabic can have more than 32 templates, our data can be a representation of the syllable structure observed in Arabic. In other words, all possible structures of the syllable are investigated since Arabic shows a heavy consonantal weight represented in the onset -coda format. Moreover, for the subjects to make judgments in a proper way, there were no distracters regarding the syllable structure for the whole word processing.

The tool was checked for validity through consulting 5 university professors and 3 senior teachers in the field. Editing and enhancing the tool followed considering the feedback of the panel. In order to establish reliability, the tool was piloted first on a class of 30 first graders yielding a Cronbach correlation coefficient of 0.93 , a value that indicates the instrument is appropriate (Hill, 1981). It has been noted that the accepted reliability standard ranges between .85 and, in more robust instruments, .90 . Since reliability is a fundamental standard in making decisions as to whether an instrument is appropriate for investigations by both researchers and teachers (Yopp, 1988), the researchers in this study carefully selected a list of words that met several criteria among which familiarity and feature analysis are but two. Following piloting the instrument to an adequate sample, the words that filtered in the instrument in its final form were 24. Considering the two tests that obtained the highest reliability coefficient in Yopp's (1988) were Roswell-Chall (1959) and Yopp-Singer with (.96) and (.95) respectively, the reliability coefficient of this instrument is indicative of the adequacy of the test for assessing learners' PA in Arabic. Based on the data obtained, the scores adopted in children classification according to PA development were: 7 or below (delayed), 8-15/24 (emerging), and 16-24/24 (developed PA).

As recommended in the literature for collecting data from early readers, our instrument was administered during April, toward the end of the first year of formal education. Collected data was analyzed using The Statistical Package for Social Sciences (SPSS) version 20. The research questions were answered using descriptive (mean and standard deviation) and inferential ( $t$ test) statistics.

\subsection{Procedures}

Since the test is based on measuring the child's ability to correctly articulate the sounds of a spoken word, the child, given the orally presented word "باب" for example, (pronounced as /bab/ in English meaning door), should respond with three separate sounds ( $/ / / / / / / / /$ / corresponding to /b///a///b/ in English). Necessary help was offered to the child when doing the four-sample words. Participants were credited one point for each word they segmented correctly. According to Yopp (1988), if the child responds correctly, I nodded, or said, "That's right". If the child gave an incorrect response, he or she was corrected. Only words that the children responded to accurately on their own were scored as correct (p. 166).

The test was administered to each student individually on a one-on-one basis. The researchers themselves administered all tasks and tests, which were tape-recorded for later transcription. An Immediate feedback was offered to the child while going through the list of the words. The directions followed when administrating the test were:

Today we're going to play a word game. I'm going to say a word, and I want you to break the word apart. You are going to tell me each sound in the word in order. For example, if I say old, you will say o-l-d. Let's try a few words together (Yopp, 1988, p. 166).

\section{Results}

Fulfilling the main goal of this study, namely developing an assessment tool for Arabic PA, the findings showed the following. First, students' overall mean score on the entire 24-word developed test was 17.94 (out of 24.00) with a standard deviation of 6.16 . Second, the test difficulty was $72.21 \%$; a value that reflects the total mean of the difficulty of each word calculated by dividing the number of correct answers on a given word by the total number of students who sat for the test. Third, at the level of individual words (Table 1), the easiest words to segment were "jarash" ( $M=.93, S D=.26)$, followed by "Anf" $(M=.91, S D=.29)$ and "Nahr" $(M=.91, S D=.29)$. On the other hand, the most difficult word to segment was "risalah" $(M=.49, S D=.50)$. Fourth, recalling that the test words represented two distinctive types of words: monosyllabic (nahr, anf, nab3, sair, laith, mawz, fawk, baid, thawb) and polysyllabic (mal3ab,qadam, jarash, risalah, 3edam, ta3am, mana5, shamal, kitaab, goyoom, dokhool, toyoor, jadeed, rabee3, sa3eed), students' mean response on mono-syllabic words ( $M=.84, S D=.25)$ was higher than the mean response on poly-syllabic ones $(M=.69, S D=.29)$. 
Table 1. Descriptives for individual test words in mean descending order

\begin{tabular}{llllllll}
\hline Word & Mean & SD & Gloss & Word & Mean & SD & Gloss \\
\hline Jarash & .93 & .26 & A Jordanian city" & sa3eed & .74 & .44 & Happy \\
anf & .91 & .29 & A nose & rabee3 & .72 & .45 & Spring \\
nahr & .91 & .29 & A river & jadeed & .70 & .46 & New \\
thawb & .88 & .33 & A dress & kitaab & .69 & .46 & A book \\
nab3 & .87 & .34 & A sprig & mana5 & .68 & .47 & Climate \\
qadam & .86 & .35 & A foot & shamal & .67 & .47 & North \\
mawz & .83 & .38 & Bananas & dokhool & .66 & .48 & Entering \\
sair & .82 & .39 & Walking & Ta3am & .65 & .48 & Food \\
baid & .80 & .40 & Eggs & 3edam & .64 & .48 & Bones \\
mal3ab & .79 & .41 & A playground & Ghoyoom & .62 & .49 & Clouds \\
laith & .77 & .42 & A proper name & Toyoor & .55 & .50 & Birds \\
fawk & .76 & .43 & Above & risalah & .49 & .50 & A letter \\
\hline
\end{tabular}

In response to the first question of the study, descriptive statistics revealed that the participants were distributed, according to Yopp's (1995) classification, as follows: 6 delayed children (with a score of 7/24 and below), 22 emerging children (with a score between 8 and 15/24), and, finally, 72 children have developed PA (with scores above 16/24).

The second research question addresses possible differences between those children who attended KG and those who did not. The results of independent sample $t$ test (Table 2) revealed a significant difference, $F(98)=.657, p$ $<.05$ in favor of the first group $(M=18.70, S D=5.78)$ compared to the second $(M=12.33, S D=6.26)$,

Table 2. Independent sample $t$ test for KG education

\begin{tabular}{lllllcccccc}
\hline & F & Sig. & T & Df & $\begin{array}{c}\text { Sig. } \\
(2 \text {-tailed })\end{array}$ & $\begin{array}{c}\text { Mean } \\
\text { Difference }\end{array}$ & \multicolumn{2}{c}{$\begin{array}{c}\text { Sd. Error } \\
\text { Diff. }\end{array}$} & $\begin{array}{c}95 \% \text { Conf. Interval } \\
\text { of the Difference } \\
\text { Lower }\end{array}$ & Upper \\
\hline $\begin{array}{l}\text { Equal variances } \\
\text { assumed }\end{array}$ & .657 & .420 & -3.55 & 98 & .001 & -6.37 & 1.79 & -9.93 & -2.81 \\
$\begin{array}{l}\text { Equal variances not } \\
\text { assumed }\end{array}$ & & & -3.34 & 13.68 & .005 & -6.37 & 1.91 & -10.47 & -2.27 \\
\hline
\end{tabular}

\section{Discussion}

Phonological awareness, it is documented, predicts success in early reading. One cannot but agree with the fact that individuals who have difficulty detecting or manipulating sounds in words will struggle with learning to read (Anthony \& Francis, 2005; Hatcher et al., 2004; Share, 1995; Snowling, 1998; Vellutino, Fletcher \& Snowling 2004). Yet, PA has not received the due attention in settings where Arabic is the target language to learn, a void that was the motive behind this study.

According to the results of our first question addressing the extent to which Jordanian children develop phonemic awareness toward the end of their first grade, it is apparent that some words like "jarash" (a name of a city), "anf" (a nose) and "nahr" (a river) obtained the highest mean scores. There are two possible accounts for these results. First, monosyllabic words take less time to be retrieved and memorized for the inflection phase in the lexicon whereas polysyllabic words have more syllables thus need more processes to be shown on the spell out phase. This would be helpful in determining the architecture of the lexicon. The word "Jarash", which elicited the highest mean response, represents an exception to the overall response for the polysyllabic words. A probable explanation for this can be based on the frequency rate this word has as the name of a local, popular, and historical city that is frequently used in daily life. The high rate of frequency this word has makes it faster to 
process since high-frequency words are faster to retrieve in the lexicon (Wilde, Goerss \& Wesler, 2003).

The second possible account is that monosyllabic words or those with light syllables are processed faster in the short memory than polysyllabic or heavy-syllable ones (Wilde, Goerss \& Wesler, 2003), which results in less reaction time allotted for phonemic segmentation. On the other hand, poly-(or heavy-) syllabic words, as in the word "risalah" (a letter) which received the mean response of .49 , would take longer processing and reaction time in the short memory. Accordingly, it is reasonable to suggest that diphthongs and consonant clusters in the onset position would make the word processing slower in the short memory. Furthermore, it is feasible to note that some explanations for the drastic differences between polysyllabic words with high rates like the word Jarash and other polysyllabic forms with very low rates like the word risala can be supported by evidence taken from the paradigmatic-nonparadigmatic (derivational) dissimilarities that exist in terms of the word processing mechanism. For words like risala, we think that it is much harder for the subjects to suggest any segmentation pattern since the relationship existing between the derived word form risalah and its root ?-r-s-l (the consonantal root) is much more opaque than the relationship shown for the paradigmatically formed word form Jarash which is even very hard to find an equivalent form within the same paradigm, i.e the word Jarash doesn't have any inflected form within one paradigm. Based upon this argumentation, we can provide cognitive evidence which entails that the possibility for the word Jarash to be processed in higher rates is more expected than the processing rate signed for derived words like risalah Given these possible justifications, the current curriculum might be in need for further research an investigation in the near future to carefully assess the occurrence frequency of polysyllabic or heavy-syllable words whose existence might be a probable cause for the delayed PA, hence reading difficulty some students encounter. In other words, there is dire need to design these curricula in accordance with templates that are not selected based upon some semantic or syntactic domains but rather on rigorous cognitive bases that take into account the frequency rates, distributions asymmetries, canonical roots, processing models and paradigmatic architecture governing the inflectional and derivational patterns in evidence provided at either the language acquisition level or learning level.

Our results indicate that the participants' mean score on the PA test, 17.94/24, is relatively high compared to those of learners of other languages. For example, Yopp (1992) found that the mean score for English native speaking children of the same age of our participants was 11.78/22. Our sample also encountered less difficulty (72.21\%) in segmenting Arabic words compared to English native speaking children of the same age (53.5\%). The difference between Arabic and English, with the first being transparent and the latter deep, may stand behind this divergence.

In congruence with these findings, our results indicating that almost three quarters of students residing in the third category, the level where children have correctly developed PA, is reassuring. But this should be read very cautiously; we do not want misreading to be misleading. What that means is that the transparent nature of Arabic has possibly contributed to students' relatively high scores. In order to be clear on that and to better serve Arabic language, more research is needed where future studies could investigate in specific the teachers' PA classroom practices and instructions with those early readers.

Based on the results of the second question, the crucial role that KG education plays in bringing up good readers emerges. Research carried out in phonological awareness and literacy in general clearly refers to the importance of the early years in the life of the child to become a good reader. Although KG education is compulsory in many countries, it is not the case in Jordan in spite of parents' belief in the importance of KG and its positive contribution to the child's literacy development. This is manifest in sending children to private KGs where many tasks and skills in phonological awareness could be developed, offering a wide chance for an early encounter with reading. The finding confirming the significant contribution of KG education in PA development supports the validity of influential documents (e.g., the report of the Committee on the Prevention of Reading Difficulties in Young Children (Snow, Burns, \& Griffin, 1998) which recommend that kindergartners develop some basic phonemic awareness by the end of their kindergarten year since enhancing children's abilities to attend to the sound structure of spoken language is a priority goal (O'Connor, Notari-Syverson \& Vadasy, 1998). After all, PA is one of the most important foundations of reading success (Every Child Reading: An Action Plan of the Learning First Alliance 1998).

\section{Conclusion}

This paper, the first to develop an instrument for and actually assessing Arabic PA among early readers of Arabic, provides reading investigators with a measurement tool and sheds light on the level of PA beginning readers of Arabic have developed by the end of their first official year of learning. The findings suggest that an overwhelming majority of the participants have already developed an adequate level of PA. The transparent 
nature of Arabic could be a reasonable justification behind this finding. The findings also support the positive contribution of KG education to PA development.

Despite the effort invested in developing the assessment tool on which the results are based in this study, further researcher is recommended for more insightful input towards comprehensive understanding of the factors contributing to reading development during the early years of schooling. Also, future research may target the impact of variables not addressed in this study but may contribute to PA development (e.g., gender, SES, geographical distribution, parents' partnership, etc.). Developing tests and tools that assess Arabic-speaking children's phonological awareness, PA in specific, that take their linguistic, cultural, and social norms into account should be at the heart of future research. Arabic should have its own valid and reliable tools; what works for a language might not work for another. Simply, one size may not fit all.

Finally, the study recommends further investigations to address phonological awareness components and the extent to which the currently adopted school curriculum systematically meets these implications. Simultaneously, the researchers foresee the need for conscious and purposeful attendance to the development of PA as a part of a broad instructional program in literacy development.

\section{References}

Abu Rabia, S. (1997a). Reading in Arabic Orthography: The Effect of Vowels and Context on Reading Accuracy of Poor and Skilled Native Arabic Readers in Reading Paragraphs, Sentences, and Isolated Words. Journal of psycholinguistic Research, 26, 465-482. http://dx.doi.org/10.1023/A:1025034220924

Abu Rabia, S. (1997b.) Reading in Arabic Orthography: The Effect of Vowels and Context on Reading Accuracy of Poor and Skilled Native Arabic Readers. Reading and Writing: An Interdisciplinary Journal, 9, 65-78. http://dx.doi.org/10.1023/A:1007962408827

Abu Rabia, S. (1999). The Effect of Arabic Vowels on the Reading Comprehension of Second-and Sixth-grade Native Arab Children. Journal of Psycholinguistic Research, 28, 39-101. http://dx.doi.org/10.1023/A:1023291620997

Adams, M. (1990). Beginning to Read: Thinking and Learning about the Print. MIT Press: Cambridge, MA.

Anthony, J. L., \& Lonigan, C. J. (2004). The Nature of Phonological Awareness: Converging Evidence from Four Studies of Preschool and Early Grade School Children. Journal of Educational Psychology, 96, 43-55. http://dx.doi.org/10.1037/0022-0663.96.1.43

Anthony, L., \& Francis, D. (2005). Development of Phonological Awareness. American Psychological Society, 14(5), 255-258.

Arab-Moghadam, N., \& Senechal, M. (2001). Orthographic and Phonological Processing Skills in Reading and Spelling in Persian/English Bilingual. International Journal of Behavioral Development, 25, 140-147. http://dx.doi.org/10.1080/01650250042000320

Baluch, B., \& Shahidi, S. (1991). Visual Word Recognition in Beginning Readers of Persian. Perceptual and Motor Skills, 72, 1327-1331. http://dx.doi.org/10.2466/pms.1991.72.3c.1327

Bruck, M., Geneseea, F., \& Caravolas, M. (1997). A cross-linguistic study of early literacy acquisition. In Foundation of reading acquisition and dyslexia (pp. 145-162). New Jersey: Hillsdale, Erlbaum.

Chard, D., \& Dickson, S. (1999). Phonological Awareness: Instructional and Assessment Guidelines. Intervention in School and Clinic, 34, 261-270. http://dx.doi.org/10.1177/105345129903400502

Ehri, L. (1991). Development of the Ability to Read Words. In R. Barr, M. Kamil, P. Mosenthal, \& D. Pearson (Eds.), Handbook of Reading Research (pp. 383-417). New York: Longman.

Essential, I. (1998). Every Child Reading: An Action Plan of the Learning First Alliance. American Educator, 22, $52-63$.

Fender, M. (2003). English Word Recognition and Word Integration Skills of Native Arabic and Japanese-speaking Learners of English as a Second Language. Applied Psycholinguistics, 24, 289-315. http://dx.doi.org/10.1017/S014271640300016X

Ferguson, C. (1959). Diglossia. Word, 1, 324-340.

Gillet, J., Temple, C., \& Crawford, A. (2004). Understanding Reading Problems: Assessment and Instruction. Boston: Allyn and Bacon.

Gordon, R. G. J. (Ed.). (2005). Ethnologue: Languages of the World. Dallas, TX: SIL International. 
Goswami, U. (2000). Phonological Representations, Reading Development and Dyslexia: Towards a

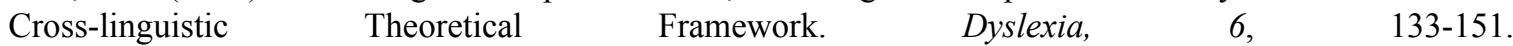
http://dx.doi.org/10.1002/(SICI)1099-0909(200004/06)6:2<133::AID-DYS160>3.0.CO;2-A

Hatcher, P., Hulme, C., \& Snowling, M. (2004). Explicit Phoneme Training Combined with Reading Instructions Helps Young Children at Risk of Reading Failure. Journal of Child Psychology and Psychiatry, 45(2), 338-358. http://dx.doi.org/10.1111/j.1469-7610.2004.00225.x

Hempenstall, K. (2006). PA: What Does It Mean? A 2003 Update. Retrieved May 1, 2013, from $\mathrm{http}: / /$ www.educationnews.org

Hills, J. R. (1981). Measurement and Evaluation in the Classroom. Columbus, OH: Charles E. Merrill.

Hulme, C., Goetz, K., \& Gooch, G. (2007). Paired Associate Learning, PA and Learning to Read. Journal of Experimental Child Psychology, 96, 150-166. http://dx.doi.org/10.1016/j.jecp.2006.09.002

Layton, L., Deeny, K., Upton, G., \& Tall, G. (1998). A pre-school Training Programme for Children with Poor Phonological Awareness: Effects on Reading and Spelling. Journal of Research on Reading, 21(1) 36-52. http://dx.doi.org/10.1111/1467-9817.00041

Moats, L. C. (2000). Speech to Print. Baltimore: Brookes publishing.

National Reading Panel. (2000). Teaching Children to Read: An Evidence-based Assessment of the Scientific Research Literature on Reading and its Implications for Reading Instruction. (NIH Publication No. 00-4769). Washington, DC: U.S. Government Printing Office.

O'Connor, R. E., Notari-Syverson, A., \& Vadasy, P. F. (1998). Ladders to Literacy: A Kindergarten Activity Book. Baltimore: Brookes.

Olofsson, A., \& Niedersoe, J. (1999). Early Language Development and Kindergarten Phonological Awareness as Predictors of Reading Problems: From 3 to 11 Years of Age. Journal of Learning Disabilities, 32(5), 464-472. http://dx.doi.org/10.1177/002221949903200512

Rathvon, N. (2004). Reading Assessment: A Practitioner's Handbook. The Guilford Press: NY.

Sensenbaugh, R. (2000). Phonemic Awareness: An Important Early Group Step in Learning to Read. Retrieved from http://www.kidsource.com/kidsource/content2/phonemic.p.k12.4.html

Share, D. (1995). Phonological Recoding and Self-teaching: Sine Qua Non of Reading Acquisition. Cognition, 55, 151-218. http://dx.doi.org/10.1016/0010-0277(94)00645-2

Snow, C., Burns, S., \& Griffin, P. (Eds.). (1998). Preventing Reading Difficulties in Young Children. Washington DC: National Academy Press.

Snowling, M. (1998). Reading Development and its Difficulties. Educational and Child Psychology, 15, 44-58.

Stanovich, K. (1994). Word recognition: Changing perspectives. In R. Barr, M. Kamil, P. Mosenthal, \& D. Pearson (Eds.), Handbook of Reading Research. New York: Longman.

Thorndike, E. L., \& Lorge, I. (1963). The Teacher's Word Book of 30,000 Words. New York: Teachers College Press. Columbia University.

Troia, G. A. (2004). Phonological Awareness Acquisition and Intervention. Current Practice Alerts. Retrieved from http://www.teachingld.org

Vellutino, F., Fletcher, J., Snowling, M., \& Scanlon, D. (2004). Specific Reading Disability (dyslexia): What Have We Learned in the Past Four Decades? Journal of Child Psychology and Psychiatry, 45(1), 2-40. http://dx.doi.org/10.1046/j.0021-9630.2003.00305.x

Wagner, D. (1993). Literacy, culture, and development. New York: Cambridge University Press.

Wilde, J, Goerss, B., \& Wesler, J. (2003). Are All PA Tests Created Equally? A Comparison of the Yopp-Singer and the Task of Auditory Analysis Skills (TASS). Journal of Research in Reading, 26(3), 295-303. http://dx.doi.org/10.1111/1467-9817.00205

Yopp, H. (1987). The Concept and Measurement of PA. PhD Diss., University of California, Riverside.

Yopp, H. (1988). The Validity and Reliability of PA Tests. Reading Research Quarterly, 23, 159-177. http://dx.doi.org/10.2307/747800

Yopp, H. (1992). Developing PA in Young Children. The Reading Teacher, 45, 696-703. 
Yopp, H. (1995). A Test for Assessing Phonemic Awareness in Young Children. The Reading Teacher, 49(1), 516-523. http://dx.doi.org/10.1598/RT.49.1.3

\section{Copyrights}

Copyright for this article is retained by the author(s), with first publication rights granted to the journal.

This is an open-access article distributed under the terms and conditions of the Creative Commons Attribution license (http://creativecommons.org/licenses/by/3.0/). 